\title{
Seroprevalence and Risk Factors Possibly Associated with Emerging Zoonotic Vaccinia Virus in a Farming Community, Colombia
}

Ashley Styczynski, Jillybeth Burgado, Diana Walteros, José Usme-Ciro, Katherine Laiton, Alejandra Pinilla Farias, Yoshinori Nakazawa, Christina Chapman, Whitni Davidson, Matthew Mauldin, Clint Morgan, Juan Martínez-Cerón, Edilson Patiña, Leidy Laura López Sepúlveda, Claudia Patricia Torres, Anyely Eliana Cruz Suarez, Gina Paez Olaya, Carlos Elkin Riveros, Diana Yaneth Cepeda, Leydi Acosta Lopez, Daniela Gomez Espinosa, Faiber Antonio Gutierrez Lozada, Yu Li, P.S. Satheshkumar, Mary Reynolds, Martha Gracia-Romero, Brett Petersen

\section{Medscape ACTIVITY}

In support of improving patient care, this activity has been planned and implemented by Medscape, LLC and Emerging Infectious Diseases. Medscape, LLC is jointly accredited by the Accreditation Council for Continuing Medical Education (ACCME), the Accreditation Council for Pharmacy Education (ACPE), and the American Nurses Credentialing Center (ANCC), to provide continuing education for the healthcare team.

Medscape, LLC designates this Journal-based CME activity for a maximum of 1.00 AMA PRA Category 1 Credit(s) ${ }^{\mathrm{TM}}$. Physicians should claim only the credit commensurate with the extent of their participation in the activity.

Successful completion of this CME activity, which includes participation in the evaluation component, enables the participant to earn up to $1.0 \mathrm{MOC}$ points in the American Board of Internal Medicine's (ABIM) Maintenance of Certification (MOC) program. Participants will earn MOC points equivalent to the amount of CME credits claimed for the activity. It is the CME activity provider's responsibility to submit participant completion information to ACCME for the purpose of granting ABIM MOC credit.

All other clinicians completing this activity will be issued a certificate of participation. To participate in this journal CME activity: (1) review the learning objectives and author disclosures; (2) study the education content; (3) take the post-test with a 75\% minimum passing score and complete the evaluation at http://www.medscape.org/journal/eid; and (4) view/print certificate. For CME questions, see page $X X X$.

Release date: November 13, 2019; Expiration date: November 13, 2020

Learning Objectives

Upon completion of this activity, participants will be able to:

- Describe demographics and characteristics of persons with VACV in the municipality of Medina in Cundinamarca Department, Colombia, according to a serosurvey and risk factor assessment

- $\quad$ Determine risk factors associated with VACV disease exposure in the municipality of Medina in Cundinamarca Department, Colombia, according to a serosurvey and risk factor assessment

- Identify clinical and public health implications of demographics and descriptive characteristics of the burden of VACV and risk factors associated with disease exposure in the municipality of Medina in Cundinamarca Department, Colombia, according to a serosurvey and risk factor assessment

CME Editor

Jude Rutledge, BA, Technical Writer/Editor, Emerging Infectious Diseases. Disclosure: Jude Rutledge has disclosed no relevant financial relationships.

CME Author

Laurie Barclay, MD, freelance writer and reviewer, Medscape, LLC. Disclosure: Laurie Barclay, MD, has disclosed no relevant financial relationships.

Authors

Disclosures: Ashley Styczynski, MD, MPH; Jillybeth Burgado, BS; Diana Walteros, MD; José A. Usme-Ciro, PhD; Katherine Laiton Donato, MSc; Alejandra Pinilla Farias, DVM; Yoshinori Nakazawa, PhD; Christina Chapman, MSPH; Whitni B. Davidson, MPH; Matt Mauldin, PhD,; Clint N. Morgan, MS; Juan M. Martínez-Cerón, MS; Edilson Patiño Castillo, MS; Leidy Laura López Sepúlveda, BSc; Claudia Patricia Torres, RN; Anyely Eliana Cruz Suarez, MPH; Gina Paola Paez Olaya, BS; Carlos Elkin Riveros Luque, DVM; Diana Yaneth Cepeda Gutiérrez, BS; Leydi Acosta Lopez, BS; Daniela Gómez Espinosa, BS; Faiber Gutierrez Lozada, DVM; Yu Li, PhD; Panayampalli Subbian Satheshkumar, PhD; Mary Reynolds, PhD; Martha Gracia-Romero, BS; and Brett Petersen, MD, MPH, have disclosed no relevant financial relationships. 
In 2014, vaccinia virus (VACV) infections were identified among farmworkers in Caquetá Department, Colombia; additional cases were identified in Cundinamarca Department in 2015. VACV, an orthopoxvirus (OPXV) used in the smallpox vaccine, has caused sporadic bovine and human outbreaks in countries such as Brazil and India. In response to the emergence of this disease in Colombia, we surveyed and collected blood from 134 farmworkers and household members from 56 farms in Cundinamarca Department. We tested serum samples for OPXV antibodies and correlated risk factors with seropositivity by using multivariate analyses. Fifty-two percent of farmworkers had OPXV antibodies; this percentage decreased to $31 \%$ when we excluded persons who would have been eligible for smallpox vaccination. The major risk factors for seropositivity were municipality, age, smallpox vaccination scar, duration of time working on a farm, and animals having vaccinia-like lesions. This investigation provides evidence for possible emergence of VACV as a zoonosis in South America.

$\mathrm{V}$ accinia virus (VACV) is a member of the genus Orthopoxvirus within the family Poxviridae. Other notable viruses in this lineage include cowpox, monkeypox, and variola (causative agent of smallpox). Because of immunologic cross-reactivity of orthopoxviruses (OPXVs), cutaneous inoculation with VACV through a worldwide vaccination campaign led to the eradication of smallpox in 1980 . However, unlike variola virus, VACV can infect nonhuman hosts (1). The origin of VACV remains unknown, but the virus is thought to have originated in continental Europe before being isolated and used as the vaccine against smallpox (2). Transmission of VACV from humans to cattle was reported during the smallpox eradication campaign, which has engendered debate over whether VACV escaped into animals as a result of vaccination efforts (3-9). Regardless of the event that led to zoonotic circulation, recent studies have demonstrated ongoing infections with related VACV

Author affiliations: Centers for Disease Control and Prevention,

Atlanta, GA, USA (A. Styczynski, J. Burgado, Y. Nakazawa,

C. Chapman, W. Davidson, M. Mauldin, C. Morgan, Y. Li,

P.S. Satheshkumar, M. Reynolds, B. Petersen); Instituto

Nacional de Salud, Bogotá, Colombia (D. Walteros, J. Usme-Ciro,

K. Laiton, A.P. Farias, M. Gracia-Romero); Universidad

Cooperativa de Colombia, Santa Marta, Colombia (J. Usme-Ciro); Universidad de Antioquia, Medellín, Colombia (J. Martínez-Cerón,

E. Patiña, L.L. López Sepúlveda); Secretaria de Salud de

Cundinamarca, Bogotá (C.P. Torres, A.E. Cruz Suarez,

G.P. Olaya, C.E. Riveros); Hospital Nuestra Señora del Pilar de

Medina, Medina, Colombia (D.Y. Cepeda); Vigilancia en Salud

Publica, Bogotá (L.A. Lopez); Universidad Javeriana, Bogotá

(D.G. Espinosa); Secretaria de Salud de Caquetá, Florencia,

Columbia (F.A. Gutierrez Lozada)

DOI: https://doi.org/10.3201/eid2512.181114 viruses in Brazil, suggesting endemic spread through a common reservoir $(10,11)$.

Several sporadic outbreaks of VACV have been reported in humans and cattle in Brazil and India, where mechanisms of transmission have been attributed to crossinoculation between teats of cows and hands of milkers (12-19). Although no reservoir has been identified, data suggest that rodents might be implicated in the transmission and maintenance of the virus (4,20-23). Furthermore, laboratory studies have demonstrated the feasibility of rodents as reservoirs $(20,24,25)$.

VACV outbreaks have proven hazardous in terms of human health and economic impact $(12,18)$, but without an identifiable reservoir, control efforts are limited to hygiene and isolation strategies. In addition, prior smallpox vaccination is not necessarily protective against VACV during outbreaks, likely because of waning immunity (17). Another potential concern is the transmission of VACV through the milk of affected cows, which has been experimentally demonstrated by the persistence of viable virus despite heat or refrigeration (26-30).

In the course of increased surveillance and education activities, Colombia has confirmed VACV infections in $\geq 3$ departments; several additional cases of similar pox-like lesions have been reported throughout the country, particularly affecting farmworkers responsible for milking cows (Andres Paez, Instituto Nacional de Salud, pers. comm., email, 2015 Oct 7). Phylogenetic analyses of isolates obtained from case-patients in Colombia demonstrate some differences from strains circulating in Brazil, although limited genetic sequencing precludes definitive determination of the source $(31,32)$. This genetic divergence suggests that VACV might be widespread in Colombia; however, its distribution and associated risk factors for transmission have not been systematically evaluated. To help clarify the burden of VACV and risk factors associated with disease exposure, we conducted a serosurvey and risk factor assessment in the municipality of Medina in Cundinamarca Department, Colombia, where several human cases of PCR-confirmed VACV infections had been reported in the preceding year.

\section{Methods}

\section{Respondent Selection}

During August-September 2016, we performed a serologic investigation of farmworkers and household members in Cundinamarca Department. We selected farms based on respondent availability from a list of farms provided by the local secretary of health. After obtaining informed consent from adults and permission from parents of children $<18$ years of age, we administered a questionnaire regarding demographic characteristics, exposures, travel history, 
and farming practices. We also collected serum samples from interviewees to correlate risk factors with serologic evidence of VACV exposure. We received a total of 134 responses and corresponding specimens from persons on 56 separate farms.

\section{Orthopoxvirus Antibody Detection}

We used IgG ELISA to evaluate the presence of orthopoxvirus-specific antibodies (i.e., anti-OPXV) as previously described (33). We coated Immulon II High Binding microtiter plates (ThermoFisher Scientific, https:// www.thermofisher.com) with purified VACV DryVax strain at $0.1 \mu \mathrm{g} / \mathrm{mL}$ in carbonate buffer, incubated overnight at $4{ }^{\circ} \mathrm{C}$, inactivated with $10 \%$ formalin, and washed 3 times with PBST (PBS with $0.05 \%$ Tween-20) by using a BioTek 405TS plate washer (Biotek, https://www. biotek.com). We then blocked plates at room temperature for 30-60 min with assay diluent containing 5\% dried skim milk, $2 \%$ normal goat serum, and $2 \%$ bovine serum albumin in PBST. After blocking, we washed plates 3 times with PBST, added serum samples at 1:100 dilution in duplicate, and incubated for $1 \mathrm{~h}$ at $37^{\circ} \mathrm{C}$. We washed plates again and added goat anti-human IgG horseradish peroxidase conjugate (KPL antibodies) (SeraCare, https:// www.seracare.com) at 1:2,000 concentration, incubated for $1 \mathrm{~h}$ at $37^{\circ} \mathrm{C}$, and washed. We then added SureBlue TMB 1-component microwell peroxidase substrate (KPL antibodies) (SeraCare) and developed for $4 \mathrm{~min}$ at room temperature before stopping the reaction with addition of equal volume of TMB Stop Solution (SeraCare). We read optical density (OD) on an Enspire plate reader (Perkin Elmer, https://www.perkinelmer.com) at $450 \mathrm{~nm}$.

For the IgM ELISA, we coated microtiter plates (Immulon II) with goat anti-human IgM KPL antibodies at 1:800 dilution in PBS (pH 7.4) and incubated overnight at $4^{\circ} \mathrm{C}$. We then washed plates 5 times with PBST by using a plate washer and blocked for $30 \mathrm{~min}$ to $1 \mathrm{~h}$ at room temperature with assay diluent buffer containing $0.5 \%$ gelatin, $2 \%$ BSA, $5 \%$ skim milk, and $2 \%$ normal goat serum in PBST. We added test serum samples at 1:50 dilution in duplicates in assay diluent and incubated for $1 \mathrm{~h}$ at $37^{\circ} \mathrm{C}$. We washed plates, added antigen (purified VACV) at a concentration of $0.5 \mu \mathrm{g} / \mathrm{mL}$, and incubated for $1 \mathrm{~h}$ at $37^{\circ} \mathrm{C}$. We washed plates again and incubated with 1:250 dilution of anti-variola virus hyperimmune mouse polyclonal ascetic fluid for $1 \mathrm{~h}$ at $37^{\circ} \mathrm{C}$, followed by washing and incubation with 1:6,000 dilution of goat anti-mouse $\mathrm{IgG}$ horseradish peroxidase conjugate (KPL antibodies) for $1 \mathrm{~h}$ at $37^{\circ} \mathrm{C}$. We then washed the plates again and developed with SureBlue TMB 1-component microwell peroxidase substrate for 8 min at room temperature, after which we added equal volume of TMB Stop Solution to each well. We read on an Enspire plate reader at $450 \mathrm{~nm}$.
We averaged OD values for known negative controls and determined a cutoff value by using the equation cutoff value: average negatives $+3 \times$ SD of negatives. We subtracted the cutoff value from the OD values of test samples. If the resulting value was $>0.05$, we considered the serum sample positive for the presence of OPXV antibodies.

\section{Data Analyses}

To identify risk factors associated with OPXV exposure, we performed a nested case-control analysis on the basis of serologic test results. We classified as case-patients those persons with a positive test for OPXV IgM or IgG, which is not specific for VACV but is a reasonable approximation of exposure (either through natural infection or vaccination), given a lack of other known circulating OPXVs in this region. Conversely, we identified as controls those persons without serologic evidence of OPXV exposure. To determine odds ratios (ORs) and 95\% CIs, we performed a complex sample analysis to account for clustering of responses and serologic outcomes by farm. Variables found to have a $p$ value $<0.1$ in bivariate analysis were included in a multivariable model analysis.

We also evaluated the correlation of farm-level characteristics with seropositivity of any persons associated with the farm. We performed bivariate analysis on individual

\begin{tabular}{|c|c|}
\hline Characteristic & Value \\
\hline \multicolumn{2}{|l|}{ Sex } \\
\hline M & $69(51.5)$ \\
\hline $\mathrm{F}$ & $65(48.5)$ \\
\hline Median age, y (range) & $45.5(12-82)$ \\
\hline \multicolumn{2}{|l|}{ Municipality of residence } \\
\hline Medina & $114(85.1)$ \\
\hline Ubala & $19(14.2)$ \\
\hline Paratebueno & $1(0.7)$ \\
\hline \multicolumn{2}{|l|}{ Education } \\
\hline None & $25(18.7)$ \\
\hline Primary & $67(50)$ \\
\hline Secondary & $22(16.4)$ \\
\hline Post-secondary & $9(6.7)$ \\
\hline Other & $11(8.2)$ \\
\hline Live in rural setting & $128(95.5)$ \\
\hline Work outdoors & 125 (93.3) \\
\hline Work with animals & $128(95.5)$ \\
\hline Self-report history of smallpox vaccination & $46(34.4)$ \\
\hline $\begin{array}{l}\text { Eligibility for smallpox vaccine (i.e., } \\
\text { respondents age } \geq 44 \mathrm{y} \text { ) }\end{array}$ & $76(56.7)$ \\
\hline \multicolumn{2}{|l|}{ Seropositivity } \\
\hline $\lg M$ & $2(1.5)$ \\
\hline $\lg G$ & $70(52.2)$ \\
\hline $\lg M$ or IgG & $70(52.2)$ \\
\hline IgM or IgG among respondents age $<44$ y & $18(31)$ \\
\hline Contact with cows & $129(96.3)$ \\
\hline Milk cows & $115(85.8)$ \\
\hline Work on multiple farms concurrently & $50(37.3)$ \\
\hline Prior knowledge of poxviruses & $28(20.9)$ \\
\hline
\end{tabular}


risk factors to determine ORs and 95\% CIs. Given that the last smallpox vaccination campaign occurred in Colombia in 1972, we separated persons on the basis of age of eligibility to have received the smallpox vaccine (34).

We subsequently built 2 multivariate logistic regression models by using individual-level risk factor data and farm survey data, respectively. We used seropositivity as the outcome variable. Using simple logistic regression, we included all variables found to be statistically significant at an $\alpha$ level of 0.1 in a stepwise model selection procedure. For individual-level risk factor data, we incorporated the variable that was most significant after being solely added to the model (if any were significant at an $\alpha$ level of 0.1 ) into the model. If any of the tested variables were no longer significant after this addition at an $\alpha$ level of 0.1 , we dropped it from the model. This process continued until no variable was found to be significant, after each was solely added to the model. We checked variables for collinearity by using Pearson correlation coefficients; values $<0.4$ were considered to not be collinear.

We conducted a similar process with the farm survey data. In that case, we also forced into the model the variable indicating whether any animals with a history of vaccinia-

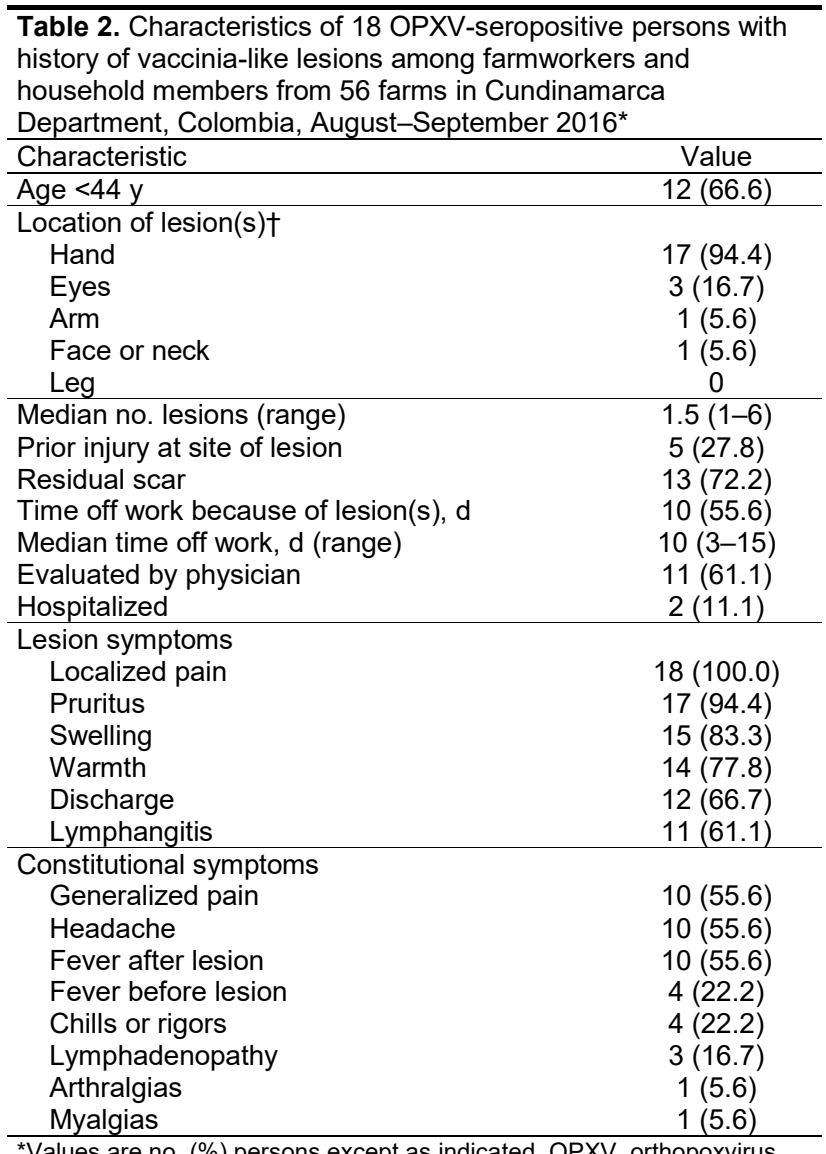

*Values are no. (\%) persons except as indicated. OPXV, orthopoxvirus. †Number of lesion locations is $>18$ because some persons had $>1$ lesion. like lesions were on the farm. We did this to evaluate the influence of suspected animal vaccinia virus infections on human seropositivity. Afterward, we conducted the same step-wise procedure.

\section{Ethics Statement}

Review by the Colombian Instituto Nacional de Salud and a human subjects advisor at the US Centers for Disease Control and Prevention determined that the activities did not meet the definition of research under 45 CFR 46.102(d). All adult participants provided informed written consent before interview participation and collection of specimens. Participants $<18$ years of age provided ageappropriate assent, and parents or guardians provided consent on their behalf.

\section{Results}

\section{Demographics and Descriptive Analysis}

Commensurate with the agricultural setting that characterizes Cundinamarca Department, participants in the investigation tended to live in rural environments and had frequent contact with animals (Table 1). Approximately equal numbers of men and women were enrolled; median age was 46 years. Based on the given age threshold (44 years of age), slightly more than half of the participants (57\%) would have been eligible to have received a smallpox vaccine before the end of the vaccination campaign. However, only $34 \%$ of participants recalled a history of smallpox vaccination.

Nearly all participants (96\%) reported contact with cows, and most of these persons participated in the milking process $(86 \%)$. Thirty-seven percent of participants reported working concurrently on multiple farms, and $\approx 21 \%$ of participants had previously heard of VACV or other poxviruses.

Laboratory analysis demonstrated that $70(52 \%)$ of the 134 participants were OPXV IgG positive, including $2(1.5 \%)$ persons who were also OPXV IgM positive, suggesting a recent exposure ( $<6$ months before). None of the participants was only positive for IgM. Excluding those born in 1972 or earlier, seropositivity for OPXV IgM or IgG was found among 18 (31\%) of 58 people included in this category (Appendix Figure 1, https://wwwnc.cdc.gov/ EID/article/25/12/18-1114-App1.pdf).

Eighteen seropositive persons also reported a history of a vaccinia-like lesion, primarily occurring on the hand (94.4\%), but 3 persons reported eye involvement (Table $2)$. Of these 18 persons, $12(67 \%)$ were $<44$ years of age, making them ineligible to have received a smallpox vaccine. The risk for symptomatic vaccinia-like lesions was not statistically different between those who self-reported smallpox vaccination and those who did not recall a 
Table 3. Multivariate analysis of OPXV IgM or IgG seropositivity among farmworkers and household members from 56 farms in Cundinamarca Department, Colombia, August-September $2016^{*}$ Variable OR $(95 \% \mathrm{Cl}) \quad \mathrm{p}$ value

Individual-level risk factors

\begin{tabular}{lcc} 
Age (dichotomous) & $3.38(1.31-8.74)$ & 0.01 \\
Smallpox scar & $5.18(1.71-15.66)$ & $<0.01$ \\
In-country travel & $0.11(0.03-0.42)$ & $<0.01$ \\
$\begin{array}{l}\text { Duration of time working at } \\
\text { current farm }\end{array}$ & $2.34(1.03-5.30)$ & 0.04 \\
Residence other than Medina & $0.26(0.07-1.04)$ & 0.01 \\
\hline $\begin{array}{l}\text { Animals with vaccinia-like } \\
\text { lesions }\end{array}$ & $5.71(0.90-36.19)$ & 0.06 \\
$\begin{array}{l}\text { Commercial feed } \\
\text { Cattle fed after milking }\end{array}$ & $0.16(0.03-0.83)$ & 0.03 \\
\hline PXX, orthopoxvirus; OR, odds ratio. & $0.19(0.03-1.15)$ & 0.07 \\
\hline
\end{tabular}

history of vaccination (OR $0.35,95 \%$ CI $0.1-1.3$ ). However, when we compared age of smallpox vaccine eligibility, being $<44$ years of age was strongly correlated with having a symptomatic vaccinia-like infection (OR $15.3,95 \%$ CI $4.2-56.1$ ).

Symptomatic persons experienced a median of 1.5 lesions, and lesions resulted in scarring in 13 of the 18 patients. Approximately one half of these persons took time off work because of their lesions, for a median of 10 days (range 3-15 days). Eleven people sought care from a physician, and 2 persons were hospitalized.

The lesions were most frequently characterized by localized pain and swelling, pruritus, and increased warmth (Table 2). Two thirds of patients also reported discharge from the lesion and lymphangitis. Many of the patients cited the co-occurrence of other symptoms including fever, malaise, and headache.

In the analysis of farm-level characteristics, 22 (39\%) of the 56 farms reported animals with vaccinia-like lesions. Cows were the only domesticated animals noted to have vaccinia-like lesions, with the exception of 1 farm that also recalled pigs having similar lesions. The lesions were located on the udders or teats in all cases; 2 farms also reported oral lesions, and 1 farm reported genital lesions. Twenty (91\%) of the 22 farms continued milking their cows in spite of the lesions. Outcomes of the lesions resulted in decreased milk production at 5 farms and caused scarring of the affected cows at 3 farms.

\section{Bivariate Analysis}

In the bivariate analysis of individual-level risk factors that we assessed, 13 variables were significantly associated with anti-OPXV seropositivity, including age as a continuous variable or as a dichotomous outcome based on eligibility for smallpox vaccination (Appendix Table 1). Age (dichotomous) and consumption of pork were the variables most strongly associated with seropositivity (OR 4.81 for age, OR 4.86 for pork consumption). Among the other significant factors were municipality of residence, self-reported history of smallpox vaccination, presence of smallpox vaccination scar, cows living on the property of residence, time spent working on the current farm, previous work on other farms, and consumption of unpasteurized milk or cheese.

In the evaluation of farm-level risk factors, 7 variables were associated with seropositivity among farmworkers at the 0.1 level (Appendix Table 2). These variables included animals with vaccinia-like lesions, type of cattle feed, habitats surrounding the farm, and humans on the farm with vaccinia-like lesions.

\section{Multivariate Analysis}

For the multivariate analysis of individual-level risk factors, 5 variables were included in the final model: age (dichotomous), smallpox vaccination scar, in-country travel in the previous 12 months, duration of time spent working on current farm, and municipality of residence. All variables were significant at the $p<0.05$ level, and none were found to be collinear. Age $\geq 44$ years, presence of a vaccination scar, and longer duration of time working on the current farm were predictive of anti-OPXV seropositivity, whereas in-country travel and residence outside of Medina were protective (Table 3).

Farm-level risk factors in the final model included animals with a history of vaccinia-like lesions, use of commercial feed, and feeding cattle after milking. Variables were significant at the $p<0.1$ level. Animals having vaccinia-like lesions was predictive of anti-OPXV seropositivity of farmworkers, but the other 2 variables were noted to be protective (Table 3 ).

\section{Discussion}

VACV is probably an emerging zoonosis in Colombia and poses a substantial health risk for the populations affected; namely, farmworkers involved in the dairy industry. In this investigation, OPXV seropositivity along with vaccinialike symptoms among farmworkers resulted in increased use of healthcare services, loss of productive work days, and dermatologic scarring at the sites of infection. VACVlike infections among cattle resulted in decreased milk production and permanent scarring of teats.

Descriptions of VACV-like infections in this population revealed mostly localized, painful, cutaneous lesions affecting the hands, similar to other descriptions of bovine-related VACV infections $(13,17,35)$. More than half of the patients also reported accompanying systemic symptoms such as fevers and malaise, and most of those affected required medical attention and time off work, indicating substantial economic ramifications. In addition, two thirds of the persons who were seropositive and reported a history of symptomatic lesions were ineligible to have received a smallpox vaccine, supporting the idea that 
unvaccinated persons are at greater risk for symptomatic disease (12).

Regarding individual-level risk factors, the association of age and smallpox vaccination scar with OPXV seropositivity is expected because these are proxy (albeit imperfect) measures of smallpox vaccination status. Rural areas of the country might have ceased smallpox vaccination before 1972, and smallpox vaccination scars can be confused with bacillus Calmette-Guérin vaccination scars. As such, the actual effect of age on VACV exposure cannot be determined. Increased age might reflect a greater opportunity for exposure, which might explain the correlation with longer duration of working on the current farm, although this correlation might not be relevant if VACV only recently emerged in Colombia. More important, nearly one third of participants who were seropositive would have been ineligible for smallpox vaccination, signifying ongoing risk for population transmission (36).

Medina was the center of the VACV outbreak; therefore, living in Medina would be expected to be associated with seropositivity. However, because our investigation was geographically centered on Medina, very few participants resided outside this municipality. A more extensive investigation of other dairy-producing areas in the country might reveal differing results. The finding that in-country travel was protective might suggest that VACV is not extensively circulating in other areas of Colombia.

The reasons for consumption of pork strongly being correlated with seropositivity in the univariate analysis are not clear, given that pigs are not known to be natural hosts of VACV. In addition, few farms in this investigation raised pigs, although nearly all participants reported consuming pork. The fact that 1 farm did report vaccinialike lesions on pigs might warrant further investigation using PCR testing. Regardless, this variable was excluded through stepwise selection in the multivariate analysis, possibly indicating a measure of confounding.

Among farm-level characteristics, the correlation of human seropositivity with animals having vaccinia-like lesions demonstrates that farmers correctly identified lesions on cattle as being consistent with VACV, although this finding does not answer the question of whether cattle acquired the infection from milkers or vice versa. The observed protective effect of commercial feed might be attributable to commercial feed being less likely to be contaminated by rodent urine and feces, which have been shown to harbor VACV $(24,25)$. Reduced VACV exposure by cattle would thus translate into reduced human exposure.

Variables that do not correlate with seropositivity might be as informative as variables that predict seropositivity. In particular, having rodents near the residence, having other household members with VACV-like lesions, consuming unpasteurized dairy products, and having cows that live on the property were not associated with seropositivity in multivariate analysis. These findings underscore that humans are more frequently infected through interaction with cows than with rodents.

VACV has been documented to spread within households, including through household fomites $(31,37,38)$, so it is somewhat surprising that having other household members with VACV-like lesions was not identified as a risk factor in this investigation. This finding might indicate that household transmission is not a primary mechanism of VACV spread and that the main means of transmission might be directly from cows to humans. Alternatively, because a high rate of respondents had contact with cows, the significance of transmission only through household contact could not be elucidated. Furthermore, an average of only 2 persons from most households participated in interviews and blood sample collection, so a more dedicated investigation might be needed to evaluate the significance of household spread.

VACV has been detected in unpasteurized dairy products (24), but the effect of such contamination on VACV transmission is unknown. In our investigation, consuming unpasteurized dairy products did not correlate with seropositivity, which might indicate that such consumption is not an important mechanism for VACV exposure. Nonetheless, additional population-level studies and testing of dairy products should be performed before negating the consumption of unpasteurized dairy products as a potential risk factor, especially given the high rate of farms that continued milking their cows despite the presence of active lesions. Further assessments regarding dairy products as a potential mechanism of disease spread will be necessary for guiding public health recommendations.

Despite an extensive questionnaire, few farming practices were found to correlate with human seropositivity. This finding could indicate that farming practices do not affect VACV transmission, but, more likely, it reflects homogeneity of farming practices that did not enable distinguishing between specific practices. Of note, all of the surveyed farms had small numbers of cattle and performed manual milking, making the risk for contact transmission either between cattle or between humans and cattle particularly germane. Additional investigation regarding animal seropositivity will be important for gaining insight into the effects of farming practices.

The findings of this investigation are similar to results from studies carried out in Brazil that found a positive correlation between age and seropositivity, although the effect of prior smallpox immunization could not be ruled out. In addition, report of animals with a history of vaccinia-like lesions was predictive of human seropositivity (39).

Clinical descriptions of painful, cutaneous lesions with associated systemic symptoms of headache, fever, 
and lymphadenopathy align closely with descriptions from Brazil during bovine-associated human outbreaks. Also similar to previous reports, vaccinia-like lesions were reported among persons who would have been ageeligible and self-reported prior smallpox vaccination, implying that prior vaccination might be only partially protective $(12,17,35,40)$.

The results of this investigation offer additional insight on the emergence of bovine-associated VACV-like infections in Colombia, which has only recently been described. OPXV seropositivity was linked to VACV-like symptoms in $13 \%$ of persons, particularly among those who had not been vaccinated against smallpox, demonstrating a substantial burden of disease in this population. However, these results do not provide a full understanding of the geographic extent of VACV circulation in Colombia, and more widespread assessments that include PCR data will be important for estimating populationlevel effects.

This outbreak investigation reveals that VACV is likely to become an increasingly important zoonosis in this part of the world, either through independent emergence events or expanding reservoir habitats against a backdrop of waning immunity. Using this type of data to clarify risk factors associated with seropositivity and disease transmission, alongside models that predict areas of disease spread, will be important for directing public health efforts to raise awareness and implement preventive measures to minimize adverse social and economic effects $(36,41)$.

\section{About the Author}

Dr. Styczynski is an infectious disease fellow at Stanford University in Palo Alto, California, USA. Her primary research interests include global infectious disease epidemiology and emerging infections.

\section{References}

1. Essbauer S, Pfeffer M, Meyer H. Zoonotic poxviruses. Vet Microbiol. 2010;140:229-36. https://doi.org/10.1016/ j.vetmic.2009.08.026

2. Carroll DS, Emerson GL, Li Y, Sammons S, Olson V, Frace M, et al. Chasing Jenner's vaccine: revisiting cowpox virus classification. PLoS One. 2011;6:e23086. https://doi.org/10.1371/ journal.pone. 0023086

3. Damaso CR, Esposito JJ, Condit RC, Moussatché N. An emergent poxvirus from humans and cattle in Rio de Janeiro State: Cantagalo virus may derive from Brazilian smallpox vaccine. Virology. 2000;277:439-49. https://doi.org/10.1006/viro.2000.0603

4. Fonseca FG, Lanna MC, Campos MA, Kitajima EW, Peres JN, Golgher RR, et al. Morphological and molecular characterization of the poxvirus BeAn 58058. Arch Virol. 1998;143:1171-86. https://doi.org/10.1007/s007050050365

5. Marques JT, Trindade GD, Da Fonseca FG, Dos Santos JR, Bonjardim CA, Ferreira PC, et al. Characterization of ATI, TK and IFN-alpha/betaR genes in the genome of the BeAn 58058 virus, a naturally attenuated wild orthopoxvirus. Virus Genes. 2001;23:291-301. https://doi.org/10.1023/A:1012521322845
6. Peres MG, Bacchiega TS, Appolinário CM, Vicente AF, Mioni MSR, Ribeiro BLD, et al. Vaccinia virus in feces and urine of wild rodents from São Paulo State, Brazil. Viruses. 2018;10:E51. https://doi.org/10.3390/v10020051

7. Medaglia ML, Moussatché N, Nitsche A, Dabrowski PW, Li Y, Damon IK, et al. Genomic analysis, phenotype, and virulence of the historical Brazilian smallpox vaccine strain IOC: implications for the origins and evolutionary relationships of vaccinia Virus. J Virol. 2015;89:11909-25. https://doi.org/10.1128/JVI.01833-15

8. Gómez Pando V, Hernán López J, Restrepo A, Forero P. Study of an outbreak of vaccinia in dairy cattle of their milkers [in Spanish]. Bol Oficina Sanit Panam. 1967;63:111-21.

9. Lum GS, Soriano F, Trejos A, Llerena J. Vaccinia epidemic and epizootic in El Salvador. Am J Trop Med Hyg. 1967;16:332-8. https://doi.org/10.4269/ajtmh.1967.16.332

10. Trindade GS, Emerson GL, Carroll DS, Kroon EG, Damon IK. Brazilian vaccinia viruses and their origins. Emerg Infect Dis. 2007;13:965-72. https://doi.org/10.3201/eid1307.061404

11. Trindade GS, Lobato ZI, Drumond BP, Leite JA, Trigueiro RC, Guedes MI, et al. Isolation of two vaccinia virus strains from a single bovine vaccinia outbreak in rural area from Brazil: implications on the emergence of zoonotic orthopoxviruses. Am J Trop Med Hyg. 2006;75:486-90. https://doi.org/10.4269/ ajtmh.2006.75.486

12. Abrahão JS, Campos RK, Trindade GS, Guimarães da Fonseca F, Ferreira PC, Kroon EG. Outbreak of severe zoonotic vaccinia virus infection, southeastern Brazil. Emerg Infect Dis. 2015;21:695-8. https://doi.org/10.3201/eid2104.140351

13. Nagasse-Sugahara TK, Kisielius JJ, Ueda-Ito M, Curti SP, Figueiredo CA, Cruz AS, et al. Human vaccinia-like virus outbreaks in São Paulo and Goiás States, Brazil: virus detection, isolation and identification. Rev Inst Med Trop São Paulo. 2004; 46:315-22. https://doi.org/10.1590/S0036-46652004000600004

14. de Souza Trindade G, da Fonseca FG, Marques JT, Nogueira ML, Mendes LC, Borges AS, et al. Araçatuba virus: a vaccinialike virus associated with infection in humans and cattle. Emerg Infect Dis. 2003;9:155-60. https://doi.org/10.3201/eid0902.020244

15. Leite JA, Drumond BP, Trindade GS, Lobato ZI, da Fonseca FG, dos SJ, et al. Passatempo virus, a vaccinia virus strain, Brazil. Emerg Infect Dis. 2005;11:1935-8. https://doi.org/10.3201/ eid1112.050773

16. Megid J, Borges IA, Abrahão JS, Trindade GS, Appolinário CM, Ribeiro MG, et al. Vaccinia virus zoonotic infection, São Paulo State, Brazil. Emerg Infect Dis. 2012;18:189-91. https://doi.org/ 10.3201/eid1801.110692

17. Silva-Fernandes AT, Travassos CE, Ferreira JM, Abrahão JS, Rocha ES, Viana-Ferreira F, et al. Natural human infections with vaccinia virus during bovine vaccinia outbreaks. J Clin Virol. 2009;44:308-13. https://doi.org/10.1016/j.jcv.2009.01.007

18. Singh RK, Hosamani M, Balamurugan V, Satheesh CC, Shingal KR, Tatwarti SB, et al. An outbreak of buffalopox in buffalo (Bubalus bubalis) dairy herds in Aurangabad, India. Rev Sci Tech. 2006;25:981-7. https://doi.org/10.20506/ rst.25.3.1708

19. Yadav S, Hosamani M, Balamurugan V, Bhanuprakash V, Singh RK. Partial genetic characterization of viruses isolated from pox-like infection in cattle and buffaloes: evidence of buffalo pox virus circulation in Indian cows. Arch Virol. 2010;155:255-61. https://doi.org/10.1007/s00705-009-0562-y

20. Abrahão JS, Guedes MI, Trindade GS, Fonseca FG, Campos RK, Mota BF, et al. One more piece in the VACV ecological puzzle: could peridomestic rodents be the link between wildlife and bovine vaccinia outbreaks in Brazil? PLoS One. 2009;4:e7428. https://doi.org/10.1371/journal.pone.0007428

21. Lopesode S, Lacerda JP, Fonseca IE, Castro DP, Forattini OP, Rabello EX. Cotia virus: a new agent isolated from sentinel mice 
in Sao Paulo, Brazil. Am J Trop Med Hyg. 1965;14:156-7. https://doi.org/10.4269/ajtmh.1965.14.156

22. da Fonseca FG, Trindade GS, Silva RL, Bonjardim CA, Ferreira PC, Kroon EG. Characterization of a vaccinia-like virus isolated in a Brazilian forest. J Gen Virol. 2002;83:223-8. https://doi.org/10.1099/0022-1317-83-1-223

23. Kroon EG, Mota BE, Abrahão JS, da Fonseca FG, de Souza Trindade G. Zoonotic Brazilian vaccinia virus: from field to therapy. Antiviral Res. 2011;92:150-63. https://doi.org/10.1016/ j.antiviral.2011.08.018

24. Abrahão JS, Trindade GS, Ferreira JM, Campos RK, Bonjardim CA, Ferreira PC, et al. Long-lasting stability of vaccinia virus strains in murine feces: implications for virus circulation and environmental maintenance. Arch Virol. 2009;154:1551-3. https://doi.org/10.1007/s00705-009-0470-1

25. Ferreira JM, Abrahão JS, Drumond BP, Oliveira FM, Alves PA, Pascoal-Xavier MA, et al. Vaccinia virus: shedding and horizontal transmission in a murine model. J Gen Virol. 2008;89:2986-91. https://doi.org/10.1099/vir.0.2008/003947-0

26. Abrahão JS, Oliveira TM, Campos RK, Madureira MC, Kroon EG, Lobato ZI. Bovine vaccinia outbreaks: detection and isolation of vaccinia virus in milk samples. Foodborne Pathog Dis. 2009;6:1141-6. https://doi.org/10.1089/fpd.2009.0324

27. de Oliveira TM, Rehfeld IS, Siqueira JM, Abrahão JS, Campos RK, dos Santos AK, et al. Vaccinia virus is not inactivated after thermal treatment and cheese production using experimentally contaminated milk. Foodborne Pathog Dis. 2010;7:1491-6. https://doi.org/10.1089/fpd.2010.0597

28. de Oliveira TM, Guedes MI, Rehfeld IS, Matos AC, Rivetti AV Jr, Alves PA, et al. Detection of vaccinia virus in milk: evidence of a systemic and persistent infection in experimentally infected cows. Foodborne Pathog Dis. 2015;12:898-903. https://doi.org/10.1089/ fpd.2015.1974

29. de Oliveira TML, Guedes MIMC, Rehfeld IS, Matos ACD, Rivetti Júnior AV, da Cunha AF, et al. Vaccinia virus detection in dairy products made with milk from experimentally infected cows. Transbound Emerg Dis. 2018;65:e40-7. https://doi.org/10.1111/ tbed.12666

30. Rehfeld IS, Fraiha ALS, Matos ACD, Guedes MIMC, Costa EA, de Souza MR, et al. Short communication: survival of vaccinia virus in inoculated cheeses during 60-day ripening. J Dairy Sci. 2017;100:7051-4. https://doi.org/10.3168/ jds.2017-12560

31. Usme-Ciro JA, Paredes A, Walteros DM, Tolosa-Pérez EN, Laiton-Donato K, Pinzón MD, et al. Detection and molecular characterization of zoonotic poxviruses circulating in the Amazon region of Colombia, 2014. Emerg Infect Dis. 2017;23:649-53. https://doi.org/10.3201/eid2304.161041

32. Smithson C, Kampman S, Hetman B, Upton C. Incongruencies in vaccinia virus phylogenetic trees. Computation. 2014;2:182-9. https://doi.org/10.3390/computation2040182

33. Karem KL, Reynolds M, Braden Z, Lou G, Bernard N, Patton J, et al. characterization of acute-phase humoral immunity to monkeypox: use of immunoglobulin M enzyme-linked immunosorbent assay for detection of monkeypox infection during the 2003 North American outbreak. Clin Diagn Lab Immunol. 2005;12:867-72.

34. Fenner F, Henderson DA, Arita I, Jezek Z, Ladnyi ID. Smallpox and its eradication - South America. Geneva: World Health Organization; 1988.

35. de Souza Trindade G, Drumond BP, Guedes MI, Leite JA, Mota BE, Campos MA, et al. Zoonotic vaccinia virus infection in Brazil: clinical description and implications for health professionals. J Clin Microbiol. 2007;45:1370-2. https://doi.org/ 10.1128/JCM.00920-06

36. Shchelkunov SN. An increasing danger of zoonotic orthopoxvirus infections. PLoS Pathog. 2013;9:e1003756. https://doi.org/10.1371/ journal.ppat.1003756

37. Costa GB, Borges IA, Alves PA, Miranda JB, Luiz AP, Ferreira PC, et al. Alternative routes of zoonotic vaccinia virus transmission, Brazil. Emerg Infect Dis. 2015;21:2244-6. https://doi.org/10.3201/ eid2112.141249

38. Assis FL, Borges IA, Mesquita VS, Ferreira PC, Trindade GS, Kroon EG, et al. Vaccinia virus in household environment during bovine vaccinia outbreak, Brazil. Emerg Infect Dis. 2013;19:20457. https://doi.org/10.3201/eid1912.120937

39. Peres MG, Bacchiega TS, Appolinário CM, Vicente AF, Allendorf SD, Antunes JM, et al. Serological study of vaccinia virus reservoirs in areas with and without official reports of outbreaks in cattle and humans in São Paulo, Brazil. Arch Virol. 2013;158:2433-41. https://doi.org/10.1007/s00705-013-1740-5

40. Megid J, Appolinário CM, Langoni H, Pituco EM, Okuda LH. Vaccinia virus in humans and cattle in southwest region of São Paulo State, Brazil. Am J Trop Med Hyg. 2008;79:647-51. https://doi.org/10.4269/ajtmh.2008.79.647

41. Quiner CA, Nakazawa Y. Ecological niche modeling to determine potential niche of vaccinia virus: a case only study. Int J Health Geogr. 2017;16:28. https://doi.org/10.1186/s12942-017-0100-1

Address for correspondence: Ashley Styczynski, Stanford University, Infectious Disease, 300 Pasteur Dr, Lane Bldg 134, Palo Alto, CA 94305, USA; email: ashley.styczynski@gmail.com 